\title{
Linking North Atlantic ocean-atmosphere teleconnection patterns and hydrogeological responses in temperate groundwater systems
}

\author{
I. P. Holman ${ }^{1}$, M. Rivas-Casado ${ }^{1}$, N. J. K. Howden ${ }^{1}$, J. P. Bloomfield ${ }^{2}$ and A. T. Williams ${ }^{2}$ \\ ${ }^{1}$ Natural Resources Department, Cranfield University, Cranfield, UK \\ ${ }^{2}$ British Geological Survey, Wallingford, UK
}

\section{Introduction}

Climate signals exhibit periodicity over a range of frequencies (e.g. diurnal, seasonal, annual and longer term climate phenomena) that are modified as they propagate through the terrestrial water cycle. Much of both our present understanding and modelling of temperate hydrological and hydrogeological systems relies on the preservation of high-frequency signals (e.g. diurnal and seasonal cycles: Holman et al., 2009; Alley et al., 2002). However, there is evidence to suggest that low-frequency oscillations in rainfall, temperature and evapotranspiration are linked to the El Ni no Southern Oscillation (Jones and Banner, 2003), Pacific Decadal Oscillation (Gurdak et al., 2007), North Atlantic Oscillation (NAO) (Schroder and Rosbjerg, 2004; Qian and Saunders, 2003) and other ocean-climate cycles.

Coupling between global climate oscillations and hydrogeological systems of the planet is poorly understood (Milly et al., 2008; Green et al., 2007), but if groundwater level dynamics are synchronized by large scale climate, then separate aquifer systems might respond similarly to climatic trends where their dynamics are entrained by environmental correlation. This would be of great societal importance in the context of climate change (Post and Forchhammer, 2002). Identifying and quantifying such couplings is a key challenge for improving understanding of long-term components of the hydrological cycle, especially given the context of a changing climate. In particular, identifying and quantifying the way in which individual climate oscillations of different periods combine to form constructive and destructive interference patterns will be crucial in improving our understanding of long-term controls on aquifer system function.

The relationship between low-frequency climatic signals and groundwater levels is complex (Figure 1). Climatic signals are filtered and lagged by the soil, unsaturated and saturated zones of aquifers, the filtering removing many high-frequency (i.e. less than 1 month) signals (Dickinson et al., 2004). The extent to which climate signals are filtered and lagged will be a function of the hydrogeological system, largely determined by travel times (i.e. a product of flow path lengths and aquifer effective conductivities), while the manner in which system is sampled (e.g. borehole location: Luque-Espinar et al., 2008) will also influence the observations.

The high-frequency filtering of climate signals provides resilience to groundwater resources and associated groundwater-dependent ecosystems under short-term climate extremes but may cause groundwater levels to exhibit a more marked response to lower frequency, large scale climate oscillations and climate change relative to, for example, variations due to isolated droughts (Dettinger and Earman, 2007). In a semi-arid context, inter-decadal and multi-decadal cycles were found in groundwater fluctuations in the High Plains Aquifer, USA (Gurdak et al., 2007) using singular spectral analysis, related to climate cycles by lag correlation. Luque-Espinar et al. (2008) identified four different cycles in groundwater levels in a Spanish aquifer using spectral analysis but found that piezometers showing the longer decadal cycles were affected by leakage from a river. Previous studies have considered 
unconsolidated or poorly consolidated granular aquifers in arid and semi-arid areas, and none have been undertaken in northern Europe, or the UK, where consolidated aquifers predominate. We describe here preliminary results for a UK chalk borehole.

\section{Study Site}

The Dalton Holme borehole [NGR SE 9651 4530] (Figure 2) in Yorkshire (northeast England) was constructed in 1895/1896 to a depth of $28.5 \mathrm{~m}$ below ground level (datum 34.5 mOD). This is a designated 'Index Borehole' and part of the UK national borehole observation network (Marsh and Hannaford, 2008), as recorded water levels are largely unaffected by abstraction. The geology of the surrounding area is predominantly glacial till deposits of Devensian age overlaying the Cretaceous Chalk, a fractured limestone aquifer. The borehole is located on the Chalk just at the feather edge of the till. In Yorkshire, the Chalk aquifer has a matrix porosity of 20-35\% (Bloomfield et al., 1995) and a mean storage coefficient of about $7 \times 10-3$ (Allen et al., 1997). Due to enhanced fracture porosity, transmissivity is typically in the range from 500 to $6000 \mathrm{~m} 2 \mathrm{~d}-1$ (interquartile range from Allen et al. 1997). Annual rainfall in the area is about $750 \mathrm{~mm}$ with an estimated annual recharge between 200 and $300 \mathrm{~mm}$ (Gale and Rutter,2006).

\section{Climate Index Data}

Data for two large North Atlantic teleconnection patterns are available from 1950 from the National Oceanic and Atmospheric Administration's Climate Prediction Centre (CPC) (CPC, 2009):

- NAO - the leading mode of atmospheric variability in the North Atlantic region, influencing the intensity and location of the North Atlantic jet stream and storm tracks. Strong positive phases tend to be associated with above-average precipitation over northern Europe in winter and vice versa.

- Scandinavia pattern - the pattern was originally named 'Eurasian Type-1' by Barnston and Livezey (1987) but it has subsequently been renamed as the 'Scandinavia pattern'. The positive phase is associated with below-average temperatures across western Europe and with above- and below-average precipitation across central Europe and Scandinavia, respectively. It has been linked to wet UK Autumns (Blackburn and Hoskins, 2001).

\section{Analyses and Results}

A univariate spectral analysis of the detrended climate indices and the Dalton Holme groundwater record identified the main cyclic components $\left(w_{i}\right)$ and describes the temporal dynamics in each individual record. Table I shows that all three data sets exhibit long periodicity (greater than 12 month) cycles, from years up to decades.

A bivariate time series spectral analysis of the groundwater record and the climate indices estimated the correlation between their corresponding cyclic Table I. Periods (in months) of the five most important long periodicity (greater than 12 months) cycles in the Dalton Holme long-term groundwater record and selected climate indices identified by univariate spectral analysis components. This method was used as it is independent of time lags between climate oscillations and the groundwater level response. Peaks in the bivariate spectral density plot (Figure 3) indicate covariance between cyclical components. The importance of peaks in the density plot is indicated by the squared coherences shown in Figure 3 . The squared coherency is a frequency-domain equivalent of correlation between the corresponding cyclical components of two time series, and varies between 0 (no linear relationship) and 1 (perfect linear relationship). 
Figure 3 shows that groundwater levels in a chalk aquifer (a major aquifer in northwestern Europe) exhibit strong annual to multi-decadal negative relationships with oscillations in NAO at periodicities of 39, 32 and 227 months. In addition, preliminary evidence suggests a positive covariance between groundwater levels and the Scandinavia pattern at a periodicity of $32 \cdot 2$ months. From this, it is inferred that there may be interference between effects of the two climate indices on groundwater cyclicity.

To our knowledge, this is the first evidence of such periodic relationships with large-scale climate systems to have been identified in a northern European groundwater level record. Further work is required to interrogate such responses in temperate groundwater systems in a systematic manner, such that implications for future groundwater dynamics and resource availability may be recognized. We hope to assess both in due course.

\section{Acknowledgements}

John Bloomfield and Ann Williams publish with the permission of the Executive Director, British Geological Survey (NERC).

\section{References}

Allen DJ, Brewerton LJ, Coleby LM, Gibbs BR, Lewis MA, MacDonald AM, Wagstaff SJ, Williams AT. 1997. The physical properties of major aquifers of England andWales. British Geological Survey Technical Report WD/97/34. British Geological Survey, Keyworth.

Alley WM, Healy RW, LaBaugh JW, Reilly TE. 2002. Flow and storage in groundwater systems. Science 296: 1985-1990.

Barnston AG, Livezey RE. 1987. Classification, seasonality and persistence of low-frequency atmospheric circulation patterns. Monthly Weather Review 115: 1083-1126.

Blackburn M, Hoskins B. 2001. The UK Record-Breaking Wet Autumn 2000 . UK Universities Global Atmospheric Modelling Programme Newsletter, Issue 24.

Bloomfield JP, Brewerton LJ, Allen DJ. 1995. Regional trends in matrix porosity and dry density of the Chalk of England. Quarterly Journal of Engineering Geology 28: S131-S142.

CPC (Climate Prediction Centre). 2009. Northern Hemisphere Teleconnection Patterns. http://www.cpc.noaa.gov/data/teledoc/telecontents.shtml. Accessed on 01/07/09.

Dettinger MD, Earman S. 2007. Western ground water and climate change-pivotal to supply sustainability or vulnerable in its own right?. Ground Water News and Views 4(1): 45 .

Dickinson JE, Hanson RT, Ferre TPA, Leake SA. 2004. Inferring time-varying recharge from inverse analysis of long-term water levels. Water Resources Research 40: W07403, DOI: 10.1029/2003WR002650.

Gale IN, Rutter HK. 2006. The Chalk aquifer of Yorkshire. British Geological Survey Research Report, RR/06/04. 68pp. 
Green TR, Taniguchi M, Kooi H. 2007. Potential impacts of climate change and human activity on subsurface water resources. Vadose Zone Journal 6(3): 531-532.

Gurdak JJ, Hanson RT, McMahon PB, Bruce BW, McCray JE, Thyne GD, Reedy RC. 2007. Climate variability controls on unsaturated water and chemical movement, High Plains Aquifer, USA. Vadose Zone Journal 6(2): 533-547.

Holman IP, Tascone D, Hess TM. 2009. A comparison of stochastic and deterministic downscaling methods for modelling potential groundwater recharge under climate change in East Anglia UK-implications for groundwater resource management. Hydrogeology Journal . (in press). DOI: 10.1007/s10040-009-0457-8.

Jones IC, Banner JL. 2003. Hydrogeologic and climatic influences on spatial and interannual variation of recharge to a tropical karst island aquifer. Water Resources Research 39(9): 1253, DOI:10.1029/2002WR001543.

Luque-Espinar JA, Chica-Olmo M, Pardo-Iguzquiza E, Garcia-Soldado MJ. 2008. Influence of climatological cycles on hydraulic heads across a Spanish Aquifer. Journal of Hydrology 354: 33-52.

Marsh TJ, Hannaford J. 2008. UK Hydrometric Register , Hydrological data UK series. Centre for Ecology and Hydrology; 210pp.

Milly PCD, Betancourt J, Kalnenmark M, Hirsch RM, Kundewicz ZW, Lettenmaier DP, Stouffer RJ. 2008. Stationarity is dead: whither water management? Science 319: 573-574.

Post E, Forchhammer MC. 2002. Synchronization of animal population dynamics by largescale climate. Nature 420(6912): 168-171.

Qian BD, Saunders MA. 2003. Summer UK temperature and its links to preceding Eurasian snow cover, North Atlantic SSTs, and the NAO. Journal of Climatology 16: 4108-4120.

Schroder TM, Rosbjerg D. 2004. Groundwater recharge and capillary rise in a clayey catchment: modulation by topography and the Arctic Oscillation. Hydrology and Earth System Sciences 8:1090-1102. 


\section{Tables}

Table 1. Periods (in months) of the five most important long periodicity (greater than 12 months) cycles in the Dalton Holme long-term groundwater record and selected climate indices identified by univariate spectral analysis

\begin{tabular}{|l|l|l|}
\hline NAO & Scandinavian pattern & $\begin{array}{l}\text { Dalton Holme groundwater } \\
\text { levels }\end{array}$ \\
\hline 32.3 & 19.4 & 12.1 \\
\hline 14.1 & 32.3 & 226.0 \\
\hline 12.3 & 339.0 & 75.3 \\
\hline 67.8 & 15.8 & 32.3 \\
\hline 24.2 & 21.2 & 19.4 \\
\hline
\end{tabular}




\section{Figures}

Figure 1. Oscillations in monthly (from top to bottom) Dalton Holme groundwater levels (with 18-month running mean), precipitation, Scandinavia pattern index and NAO index (1950-2006).
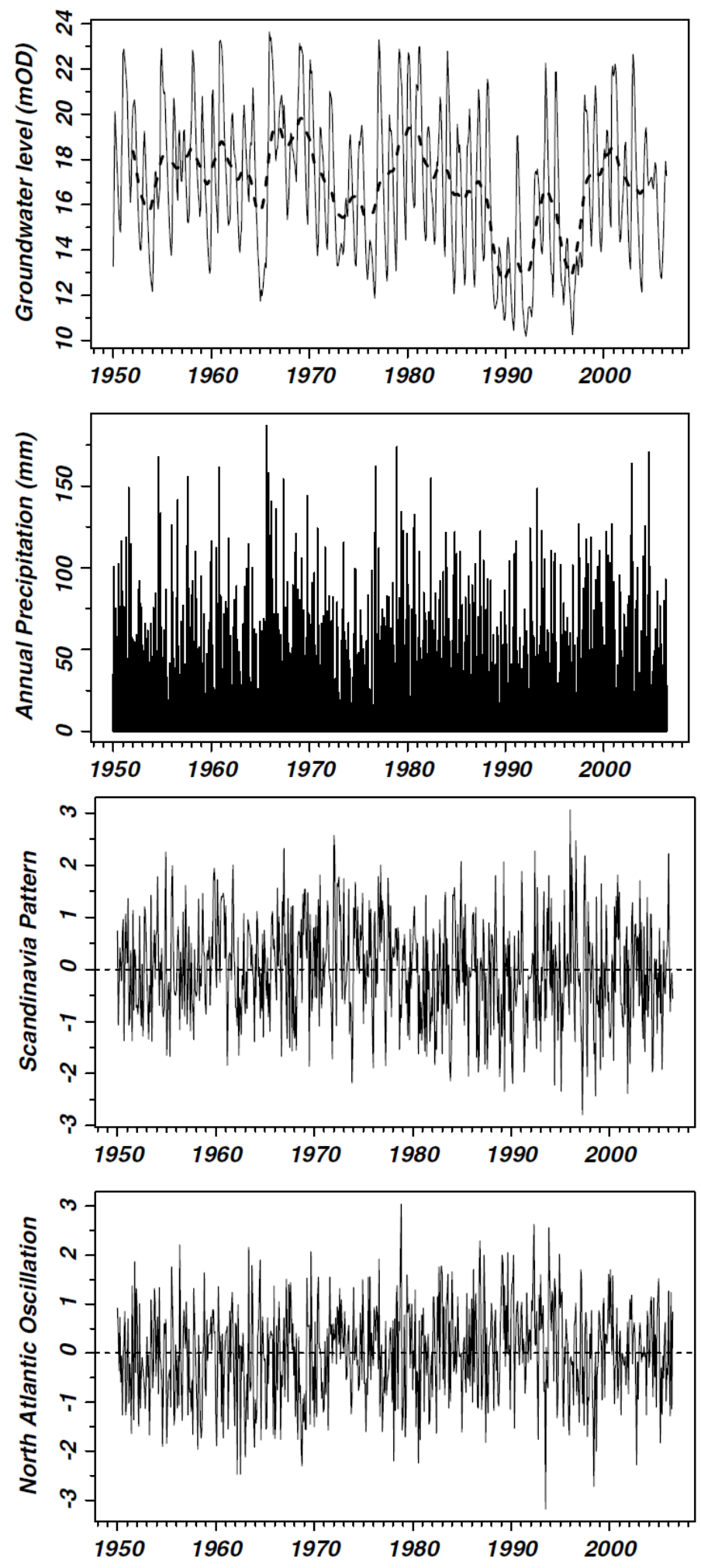
Figure 2. Location of the Dalton Holme borehole.

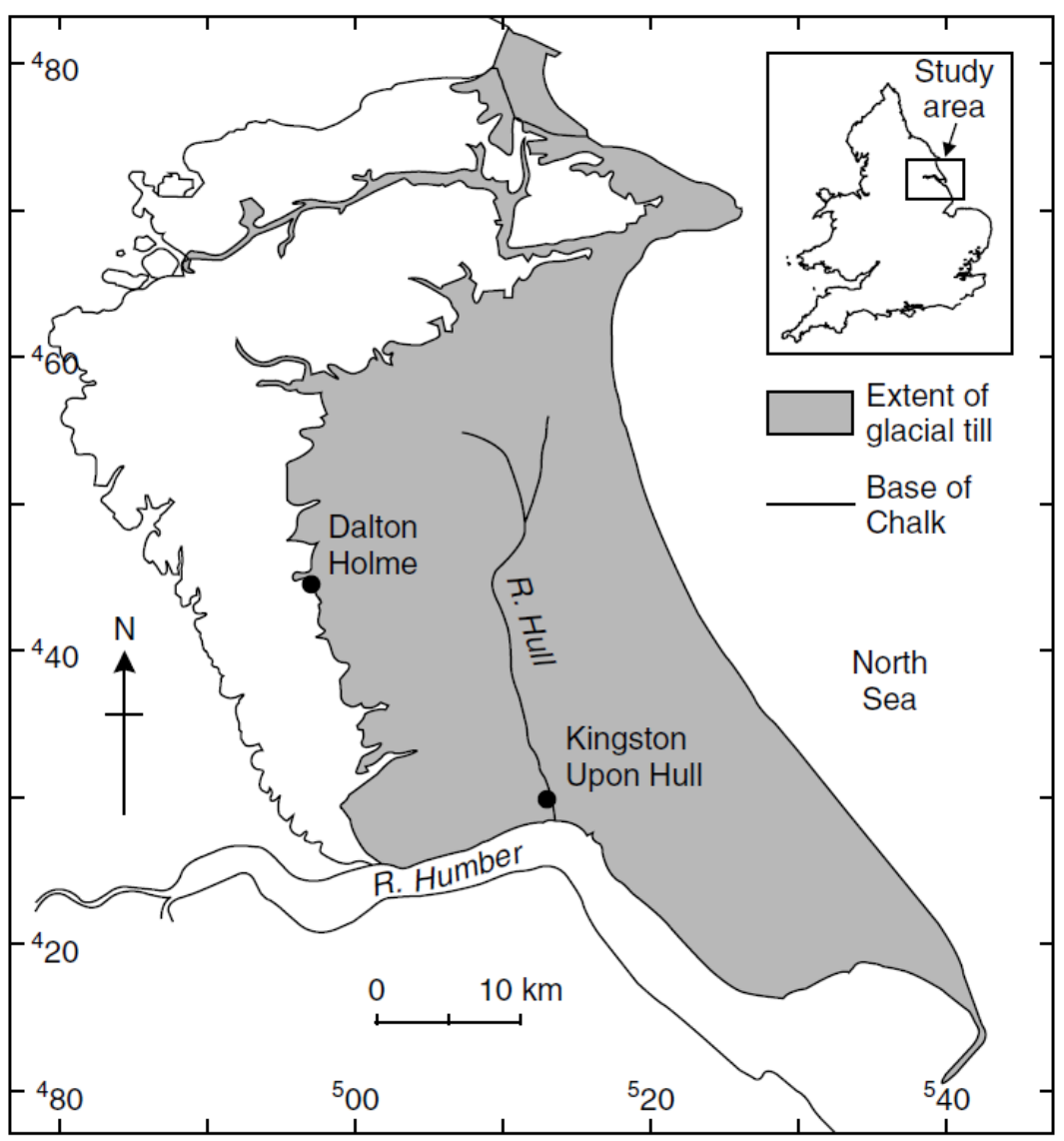

Figure 3. Bivariate spectral analysis of detrended groundwater levels at Dalton Holme with (left) the NAO and (right) Scandinavian pattern. Selected covariance peaks in the cospectral density, between the cyclical components of the groundwater levels and the climate indices, are associated with high coherency (Labels give periodicity in months).
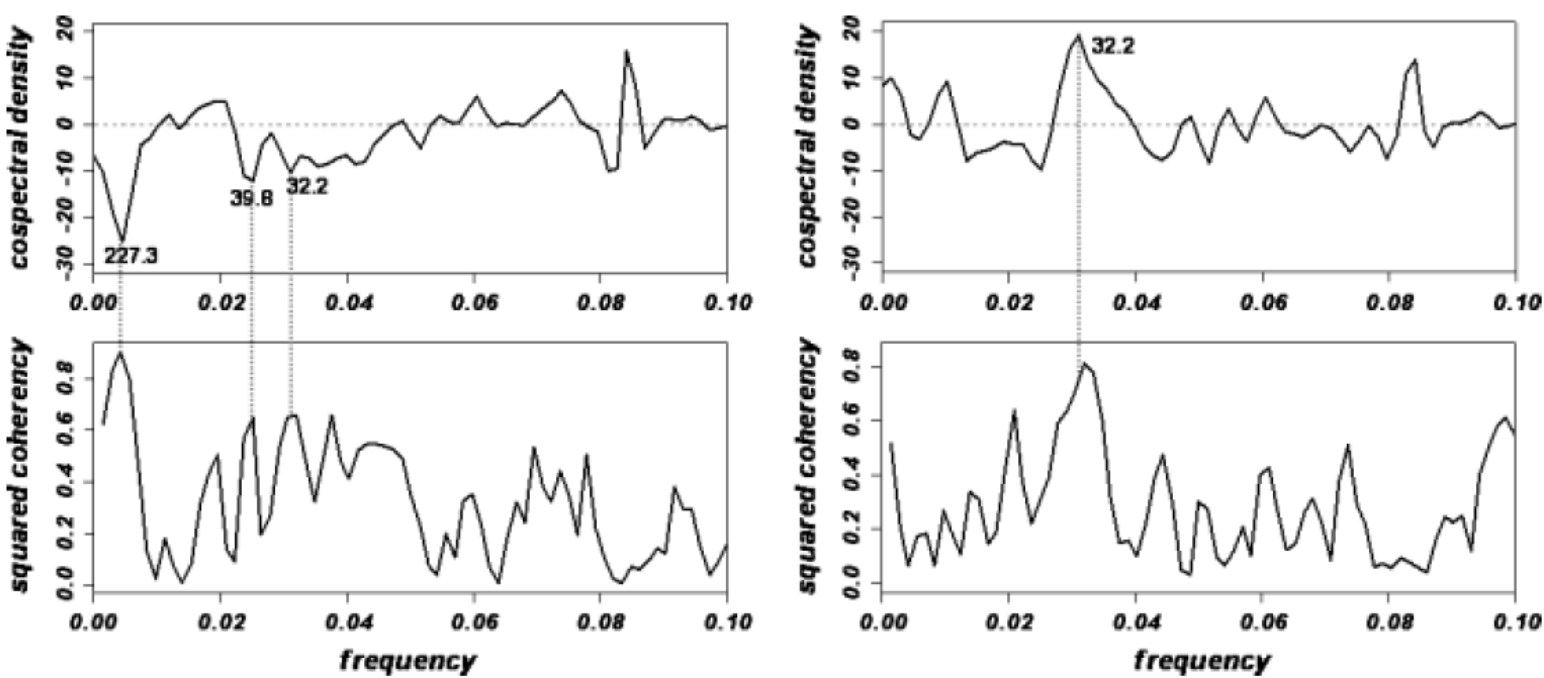


\section{Figures}
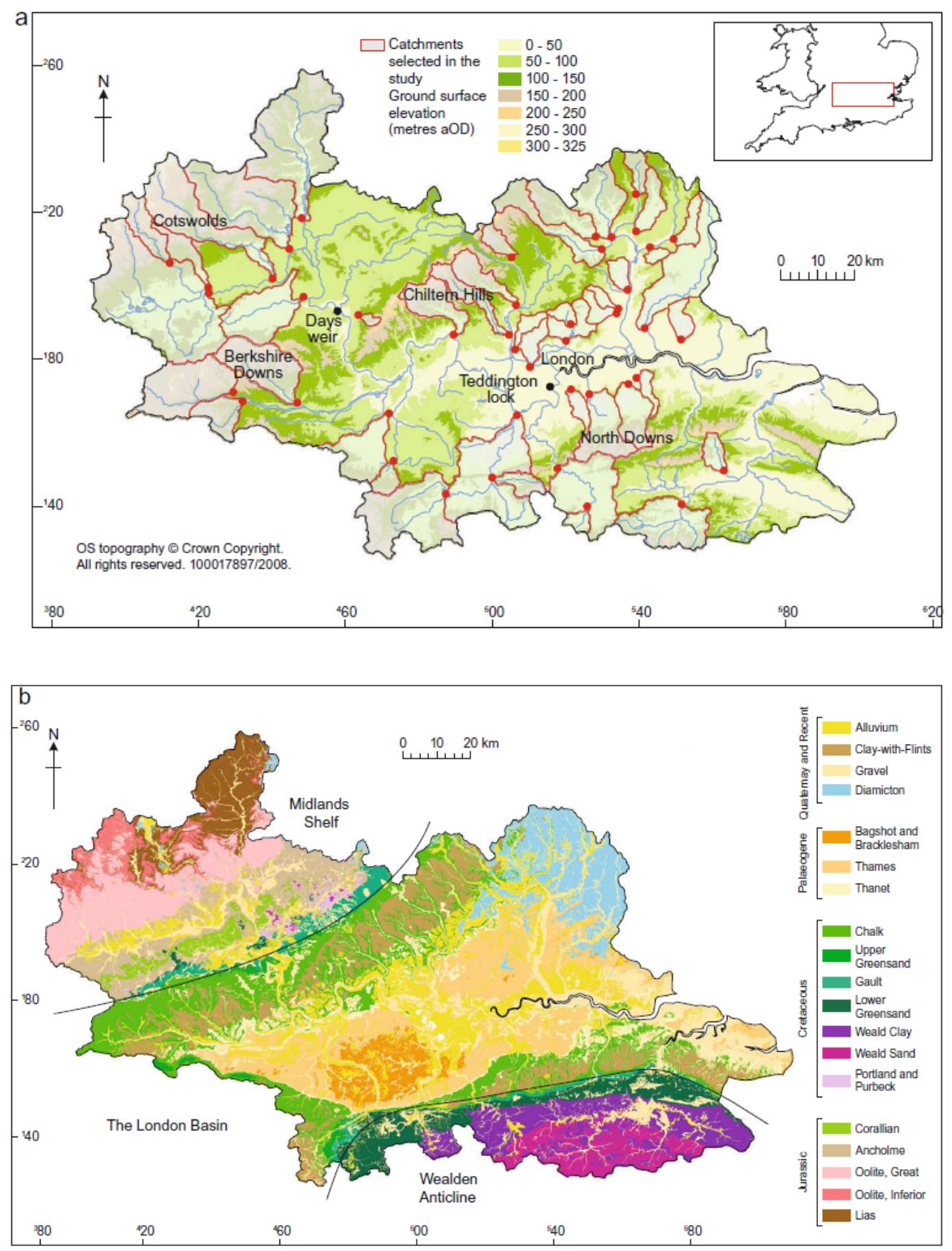

Fig. 1. Maps of the Thames Basin showing, (a) physiography, rivers and the 44 catchments used in the study for calibration and (b) the distribution of the 19 lithological classes used as the basis of regression Models 1a and 1b. 


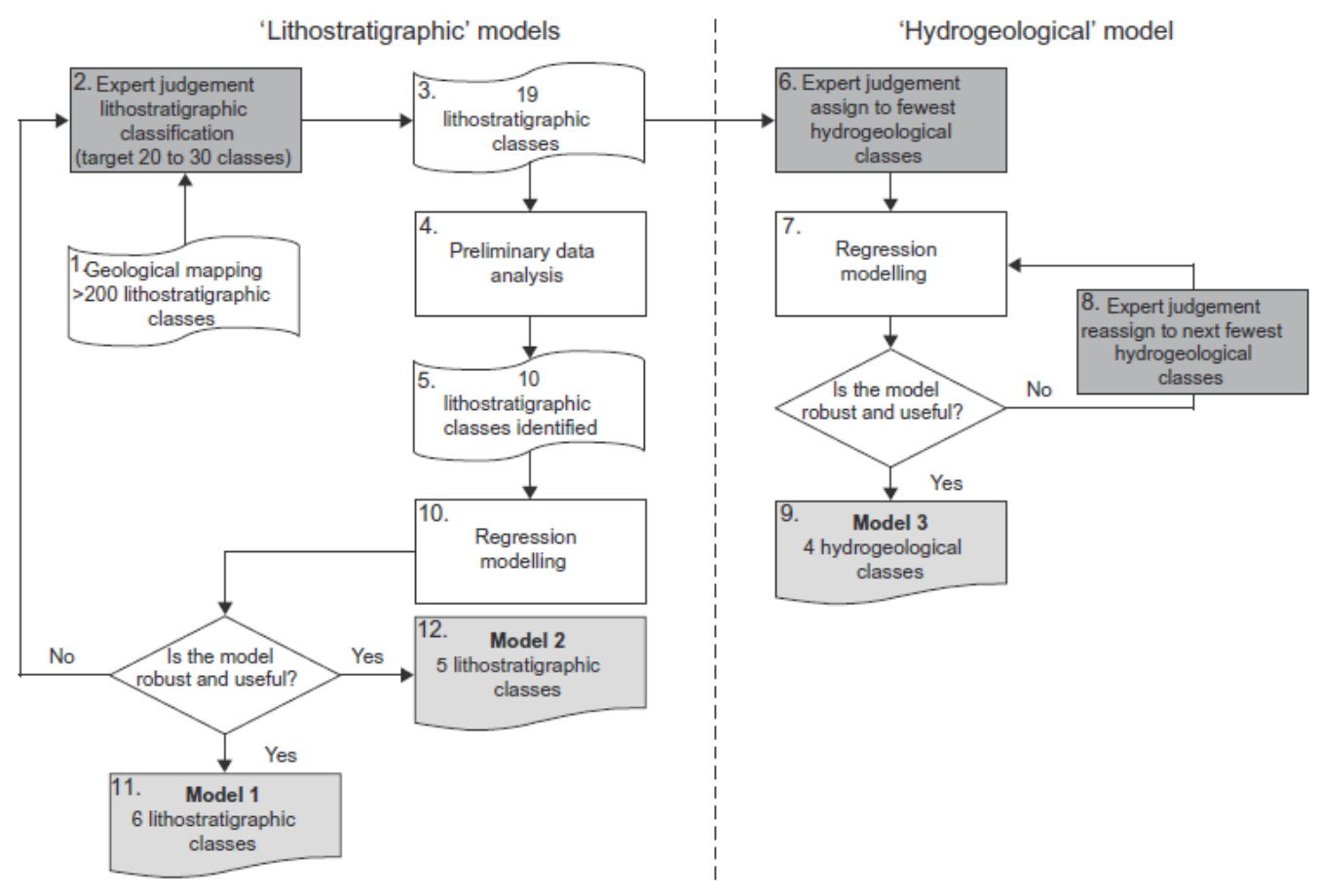

Fig. 2. A schematic illustration of the regression methodology showing the iterative development of the models. Models $1 \mathrm{a}$ and $1 \mathrm{~b}$ were developed based on lithostratigraphic classification of geological mapping, and Model 2 was based on a hydrogeological interpretation of the lithological classification.

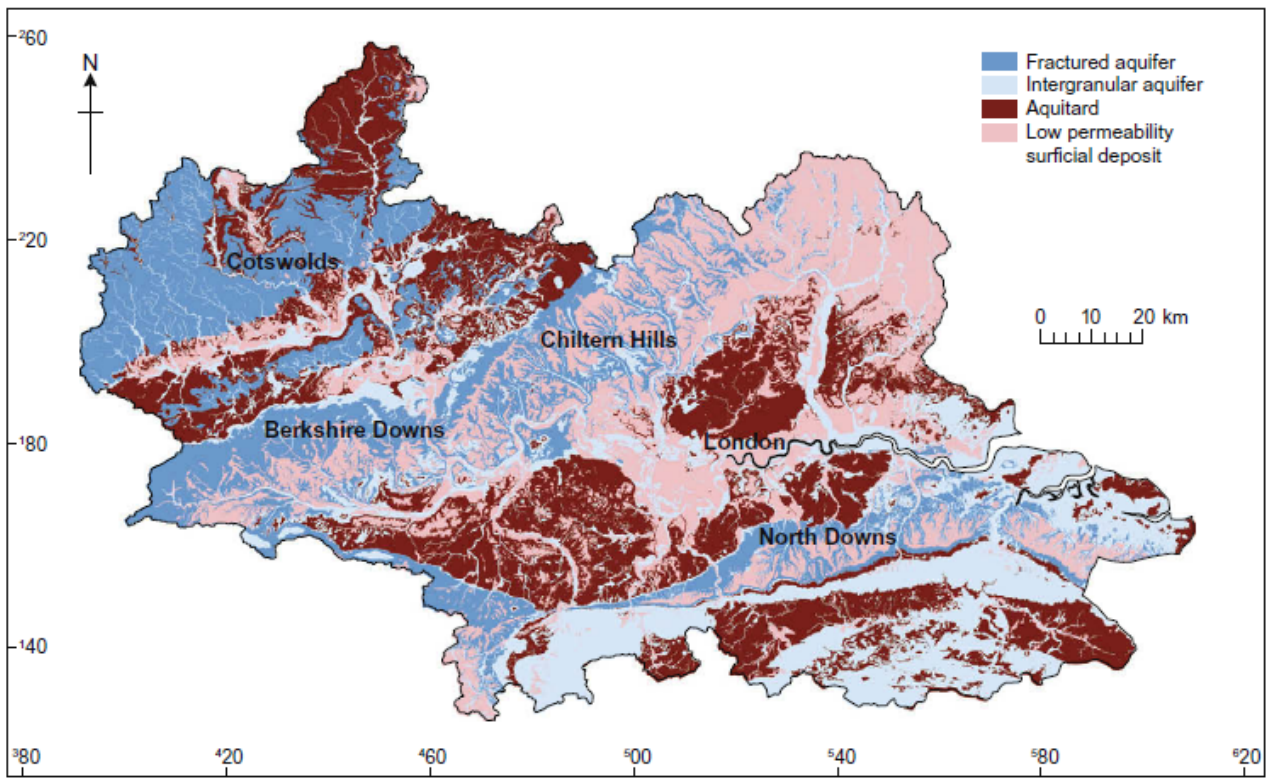

Fig. 3. Map of the Thames Basin showing the distribution of the four main hydrogeological classes used in regression Model 2. 

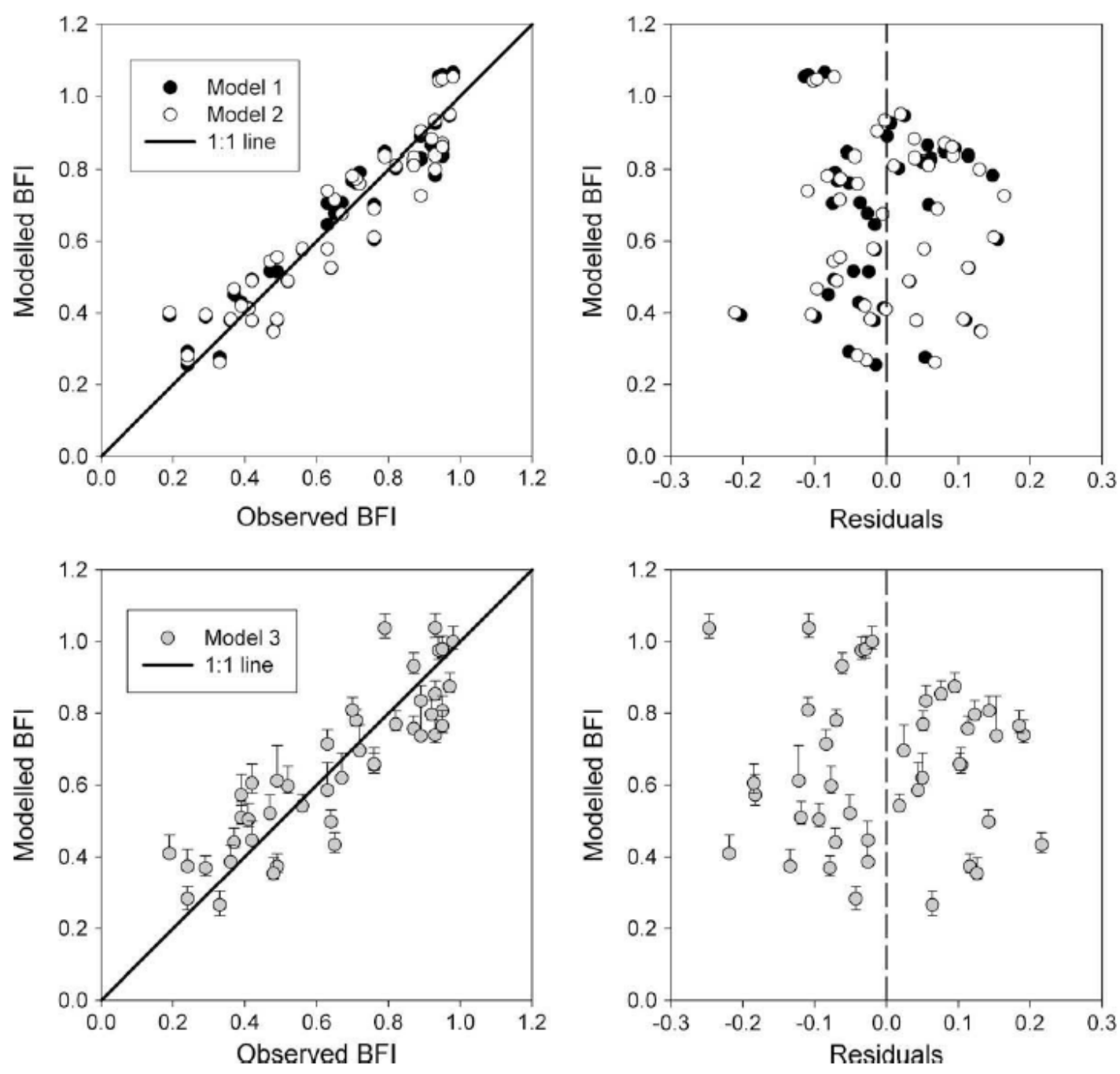

Fig. 4. Plots of modelled BFI against observed BFI and model residuals for the 44 calibration catchments for Models 1a, 1b, and 2. Confidence bounds on BFI values for Model 3 are based on the $5 \%$ tile and $95 \%$ tile values for a Monte Carlo simulation using bootstrap statistics for the model. 


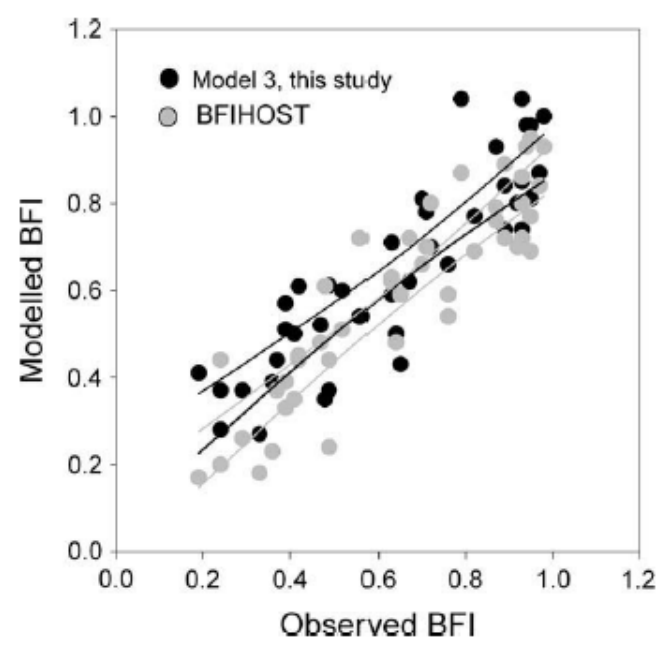

Fig. 5. Comparison between observed and modelled BFI for the 44 calibration catchments for this study and for BFIHOST. The $90 \%$ confidence bounds to linear regressions through the two respective data sets are also shown.

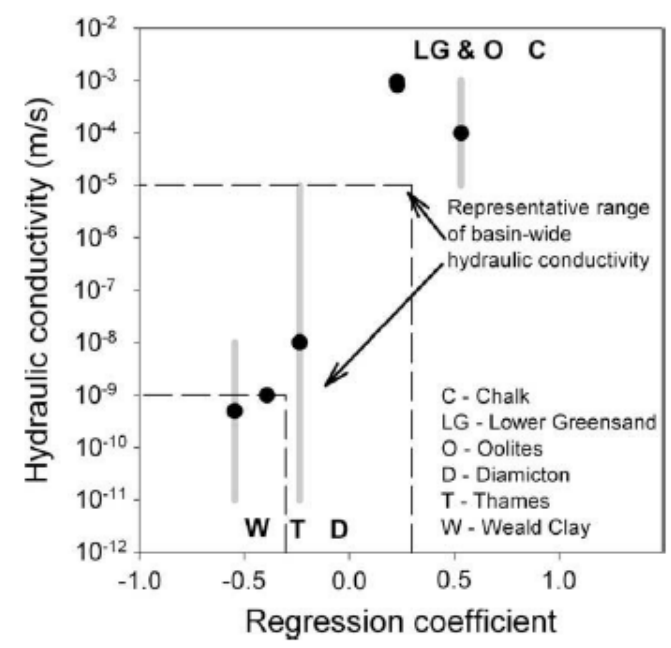

Fig. 6. Relationship between regression coefficients for Model 1a and estimates of the hydraulic conductivity for each lithostratigraphic class in the model. The dashed lines bracket the inferred range of representative hydraulic conductivity for the Basin as a whole. 


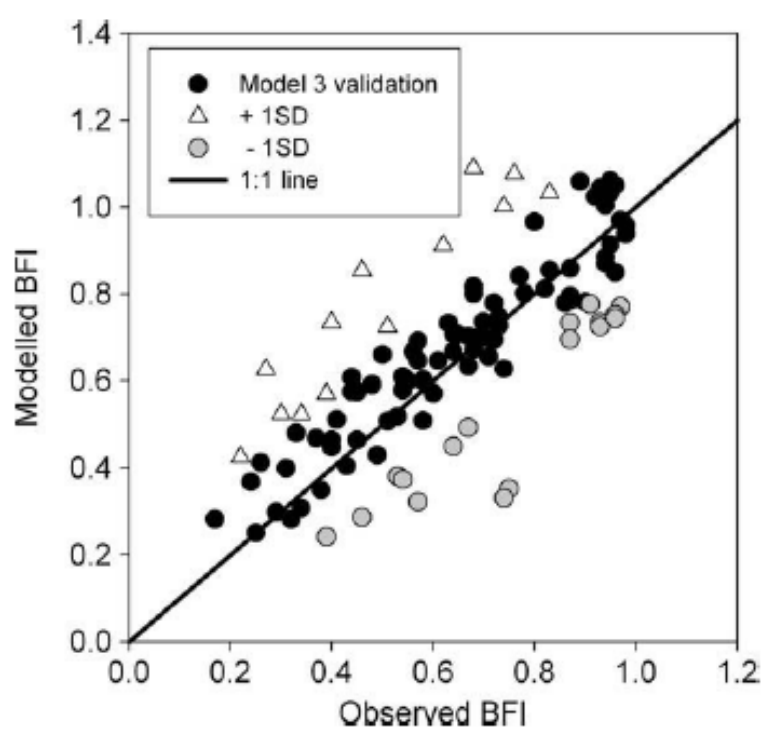

Fig. 7. Modelled against observed values of BFI for 110 'variably impacted' catchments in Thames Basin based on Model 2 with outliers identified.

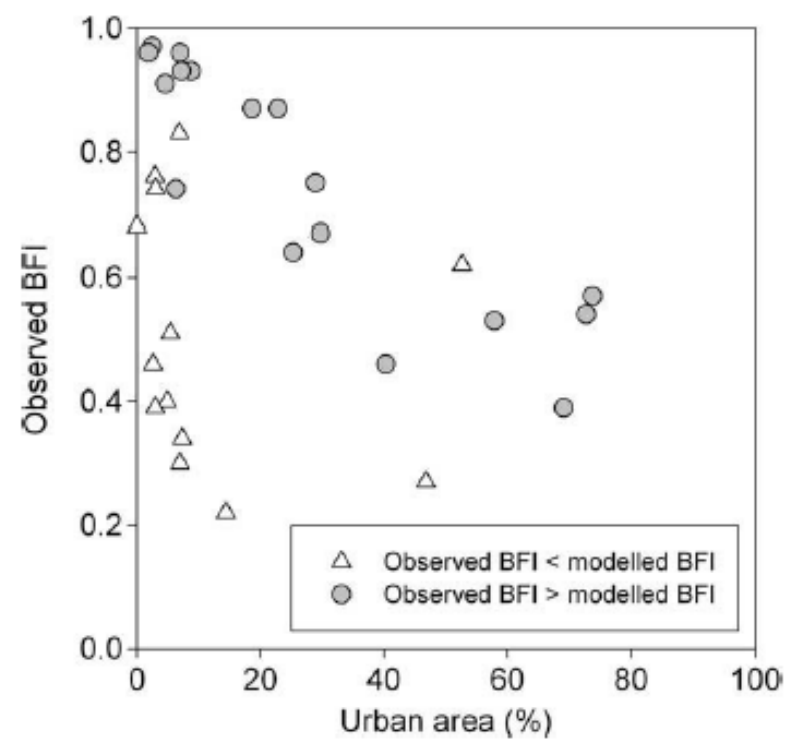

Fig. 8. Observed BFI as a function of percentage urban area for the outliers identified in Fig. 7. 